\title{
To understand the reproductive tract microbiome associated with infertility through metagenomics analysis
}

\author{
Manisha Vajpeyee ${ }^{1 *}$, Lokendra Bahadur Yadav ${ }^{1}$ Shivam Tiwari ${ }^{1}$ and Parikshit Tank ${ }^{2}$
}

\begin{abstract}
Background: Knowledge of the microbiome is in its infancy in health and human illness, especially concerning human reproduction. We will be better able to treat dysbiosis of the reproductive tract clinically if it is better explained and understood. It has been shown that altered vaginal microbiota affects parturition, and its function is uncertain in assisted reproductive technologies. However, the effects of recognized microbes such as Mycoplasma tuberculosis, Chlamydia trachomatis, and Neisseria gonorrhoeae are well established, resulting in subclinical changes which are considered to be risk factors for infertility and poor reproductive outcomes.

Main body: Recent studies indicate that the vaginal tract comprises several different organisms of the microbiome. Some microbiota can play an important role not only in the reproductive tract but also in overall health. The microbiome of the female reproductive tract has been identified mainly based on studies that examine vaginal samples across many reproductive technologies, using a metagenomics approach.

Conclusion: Alteration of reproductive tract microbiota or presence of certain microbiota irrespective of the level of pathogenicity may interfere with fertilization, implantation, and subsequent embryo development. This may lead to failed fertility treatments and reduced live birth rate (LBR).
\end{abstract}

Keywords: Reproductive microbiome, In vitro fertilization, Semen microbiome, Lactobacillus, Metagenomics

\section{Background}

Infertility is a common problem. Approximately $10 \%$ of couples face delays in conception. Of these, $10 \%$ will have unexplained infertility. In human beings, microbes have a major impact on human health and may cause infectious diseases. These changes in the microbiome may result in infertility and failure of recent therapies. The microbiome may be overlooked in such circumstances as an implicated factor. Microbial communities can be found in the semen, vagina, and urethra. Microbiome composition and interactions with different parts of the human body have an effect on human health and influence various disease processes $[1,2]$.

\footnotetext{
* Correspondence: researchudr@gmail.com

'Department of Reproductive Medicine and Research, Pacific Medical University and Hospital Bhilon Ka Bedla, Udaipur, Rajasthan 313001, India Full list of author information is available at the end of the article
}

The polymerase chain reaction (PCR) method and routine culture method which are used to determine the presence of particular aerobic, anaerobic, or pathogenic bacterium are present in clinical specimens. Large-scale microbial DNA and RNA sequences can be extracted directly from human mixed microbial communities using next-generation sequencing technologies. It could be used in sequences of microbes that have not been cultured [3, 4]. The "microbiota" is the microorganisms that live in the vagina and have a mutual relationship with the host "microbiome" [5]. In women, the glycogen deposition in the vaginal epithelium may encourage the growth of glucose-fermenting microorganisms like Lactobacillus species since women of reproductive age have a high level of circulating estrogens [6]. Human vaginal microbes that promote pregnancy conception and timing of delivery may have increased the chance of risk
Springer Open (c) The Author(s). 2021 Open Access This article is licensed under a Creative Commons Attribution 4.0 International License, which permits use, sharing, adaptation, distribution and reproduction in any medium or format, as long as you give appropriate credit to the original author(s) and the source, provide a link to the Creative Commons licence, and indicate if changes were made. The images or other third party material in this article are included in the article's Creative Commons licence, unless indicated otherwise in a credit line to the material. If material is not included in the article's Creative Commons licence and your intended use is not permitted by statutory regulation or exceeds the permitted use, you will need to obtain permission directly from the copyright holder. To view a copy of this licence, visit http://creativecommons.org/licenses/by/4.0/. 
factor infections, and as we know, a healthy balance of the microflora in the vaginal microenvironment is directly associated with good health. In this review, we will focus on the reproductive axis microbiome to establish interactions between the diversity of microbes and infertility and which are predominantly found in different parts of human reproductive samples. Huge interest is being paid to the vaginal microbiome, but endometrial, follicular, and semen microbiome are starting to gain attention regarding infertility with different processes, i.e., $16 \mathrm{~S}$ rRNA gene sequencing, metagenomics, and pyrosequencing.

\section{Main text}

\section{Metagenomics: 165 rDNA amplicons sequencing}

With the help of metagenomics, strategies may have the capability to direct examining the microbial composition and phylogenetic diversity associated with an incredibly complex microbial population. A diverse population can be exploited by targeting universal and conserved genes such as rRNA genes to classify microbes using a basic approach.

Microorganisms are like especially bacteria and archaea, which can be detected in 16S rRNA genes by amplifying unique target regions with a combination of conserved primer binding sites and intervening variable sequences to facilitate genus and species identification. Since various bacteria families have different 16S rRNA gene sequences, this gene sequencing is often used for bacterial species identification. Bacteria have 16S rRNA gene and 9 hypervariable regions [V1-V9] comprised to intersperse conserved variable sequence. Hypervariable regions are about 50-100 bases long, and these sequences vary in terms of variance and usefulness for universal microbial identification (Fig. 1).

\section{Next-generation DNA sequencing: pyrosequencing}

Over the last decade, rapid parallel high throughput sequencing has led to the widespread commercialization of next-generation sequencing technology. Pyrosequencing biochemistry has recombinant enzymes these enzymes included single-stranded binding protein and sequencing have capability to read lengths improved due to refinements, during the past decade. With the help of advanced microfluidics technology, instruments have the ability to increase sequencing reaction cycle speed and, in second- and third-generation sequencers, the number of cycles that can be performed per unit time. For metagenomics sequencing, 454 technologies have a large number of reeds and a much greater range of coverage as compared to Sanger sequencing [7] (Fig. 2).

\section{Next-generation microbial identification strategies: metagenomics and informatics}

Metagenomics' analytical branch investigates how hundreds or thousands of organisms can be accurately identified which is a reasonable amount of time and at a reasonable cost. For large-scale projects, current

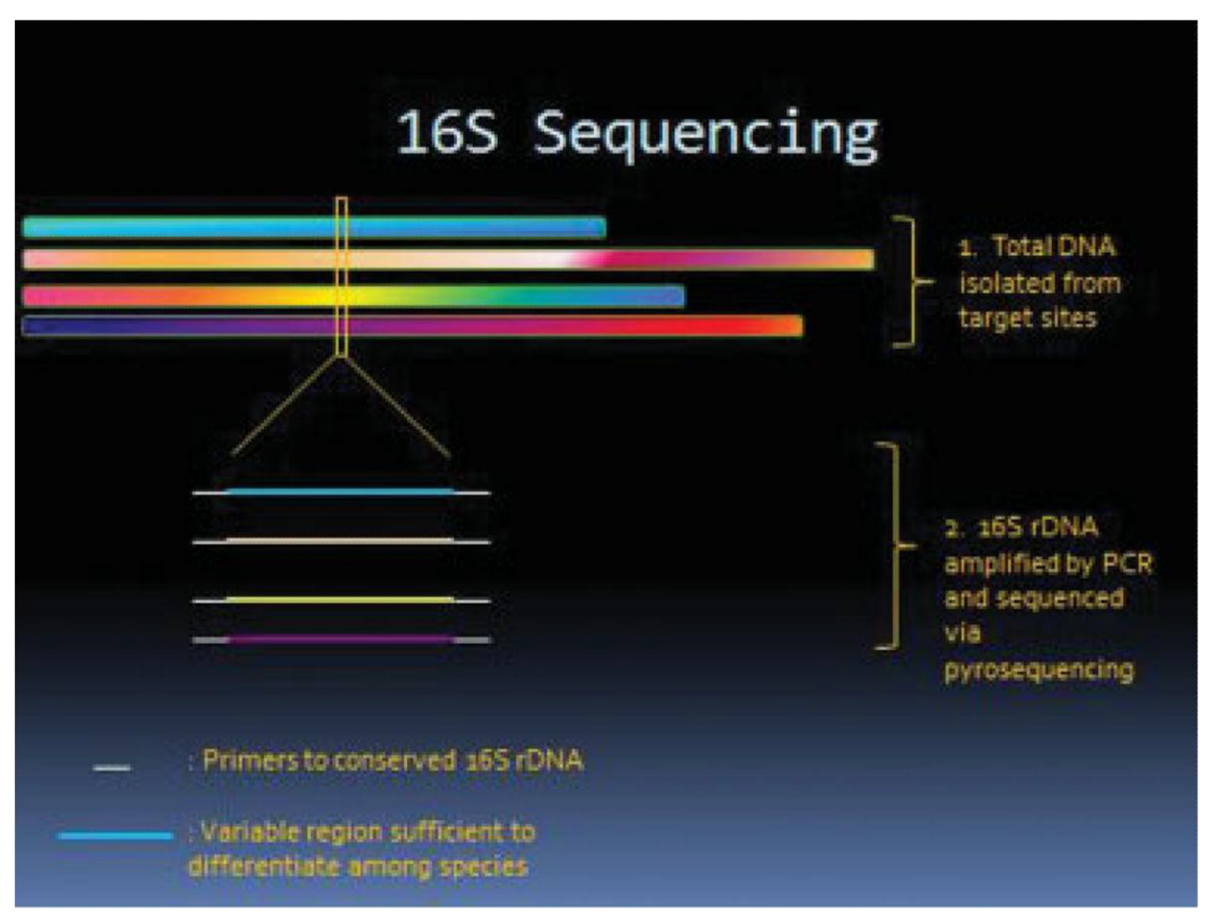

Fig. 1 16S rDNA for microbiota identification 

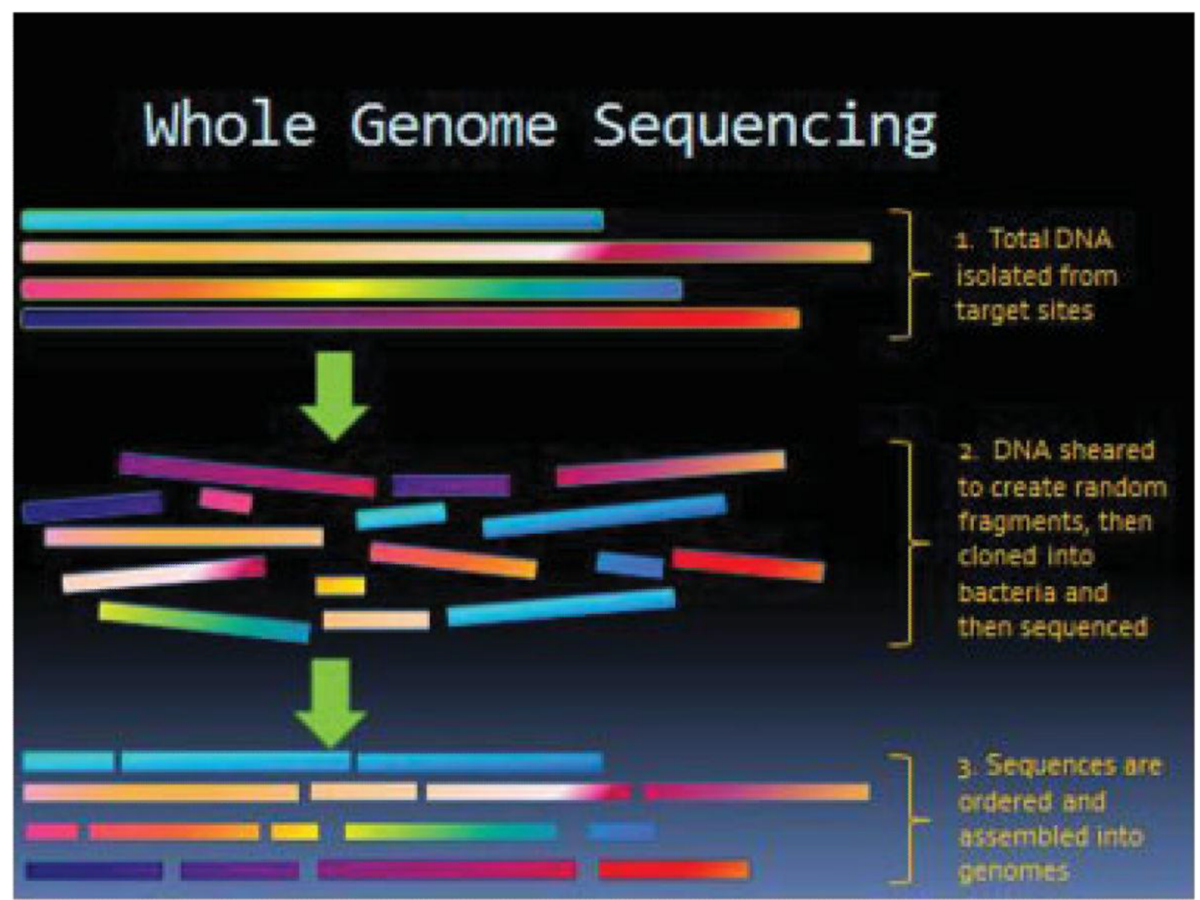

Fig. 2 Whole genome sequencing for microbiota identification

bioinformatics throughput is too slow and insufficiently automated. The scientific community needs to establish a high-throughput metagenomics rDNA analysis tool. In the current metagenomics data analysis, adequate computational power and distributed computing networks are needed in research. Robust server technology could eventually meet these requirements which are necessary for metagenomics analysis.

\section{Microbiome and reproduction}

Human microbiomes are important in human health and disease, with some etiologies still unknown. Microbial communities exist in the human skin, gastrointestinal tract, oral cavity, and reproductive tract.

The compositions of the microbiome present in the various parts of the human body and have an impact on human health and disease origin $[8,9]$. In clinical specimens, the polymerase chain reaction method and routine culturing methods can be used to identify particular aerobic, anaerobic, or pathogenic bacteria. Human mixed microbial communities and microbial DNA and RNA directly extracted large scale can also be used sequencing microbiomes with the help of next-generation sequencing technology that could not be cultured [10]. Furthermore, next-generation sequencing is more effective and less costly than Sanger sequencing [11]. The most common method for studying culture-independent microbiomes is $16 \mathrm{~S}$ ribosomal RNA analysis.
Next-generation sequencing and bioinformatics techniques for sequencing $16 \mathrm{~S}$ ribosomal RNA can be used to identify microbiomes.

\section{Vaginal microbiota}

Although it has been shown that the vaginal microbiota influences childbirth, its function in assisted reproductive technology is unknown. Subclinical changes caused by pathogens including Mycoplasma tuberculosis, Chlamydia trachomatis, and Neisseria gonorrhoeae have been linked to infertility. The vaginal tract presents many different species of Lactobacillus, with few that predominate and have recent findings to demonstrate.

The colonization of the transfer-catheter tip with Lactobacillus crispatus could play an important role during embryo transfer, with Lactobacillus crispatus having the potential role to increase implantation and as well as live birth rates while decreasing infection rates, according to this study in assisted reproductive technology vaginal microbiomes [12]. Additionally, some research indicates that progesterone-resistant endometrium increases the likelihood of an irregular vaginal microbiome. The most common pathogen is Lactobacillus, which is essential for vaginal health [13, 14]. Lactobacillus produces a large amount of lactic acid during anaerobic glycogen respiration, making the vaginal atmosphere acidic, which may help to prevent bacterial propagation. Lactobacillus species may produce hydrogen peroxide, which can inhibit pathogenic bacteria 
growth by sterilization and disinfection, lactobacillus bacteria as well as possessive nutritive and competitive effects that may compete with other nutrients that inhibit pathogenic bacteria growth. Lactobacillus is an essential component of the vaginal flora's distribution and balance [15].

\section{Microbes present in follicular fluid}

Oocytes mature in the follicular fluid environment, and developing follicular fluid must be colonized by microbiota, and women undergoing IVF cycles are not sterile. It is critical to distinguish between contamination and in vivo colonization procedures because follicular fluids were labeled as either contaminant or detectable microbiota. During transvaginal oocytes retrieval and colonization, lactobacillus microbiota in follicular fluid was also detected in the vagina, while microbiota was only found in follicular fluid. Lactobacillus spp the most common lactobacillus bacteria in follicular fluids are Lactobacillus crispatus, Lactobacillus gasseri, Actinomyces spp., and Propionibacterium spp.

Because Lactobacillus spp. was discovered in follicular fluid and linked to improved embryo quality, which resulted in substantially higher rates of embryo transfer and pregnancy, it suggested that follicular fluid contains a microbiome that can affect IVF treatment outcomes $[16,17]$. Lactic acid, a major acid metabolite generated by Lactobacillus spp., has antimicrobial properties that can protect oocytes from harmful microbiota while they mature [18]. While human follicular fluid is considered sterile, it is easily contaminated through the transvaginal collection route, and little is known about its ability to promote microbial growth.

\section{Endometrial microbiomes}

The endometrium is the innermost lining layer of the uterus and is made of numerous glands embedded within the supportive stroma. The endometrial microbiota plays a very important role at the embryo transfer in the initiation of pregnancy in reproductive medicine, and a better understanding of what a healthy uterine environment and how to achieve it would benefit not only IVF patients, but also any woman who wants to conceive [19]. Uterine infection is a recognized cause of infertility because it can cause inflammation and immune activation in the endometrium, preventing embryo implantation and the start of a healthy pregnancy [19].

There are several groups have found in the endometrial flora at the time using microbial culture of the distal tip of the transfer catheter in the 1990s and 2000s, which was recorded by several groups assessing the endometrial flora at the time of ET using microbial culture of the distal tip of the transfer catheter $[19,20]$.
When endometrial microbial pathogens such as Streptococcus spp., Staphylococcus spp., Enterococcus spp., Escherichia coli, Klebsiella pneumoniae, and gramnegative bacteria were isolated, the reproductive outcome was consistently low [19-23] compared to cases with negative culture. The endometrial microbiome has been studied more thoroughly, and advances in bacteria identification using cultivation-independent techniques have been made, allowing for the characterization of low microbiota populations. Lactobacilli, like the vaginal microbiota, dominate the endometrium of healthy and asymptomatic people [24].

\section{Lactobacillus crispatus}

Lactobacillus crispatus-dominated communities can have lower vaginal $\mathrm{pH}$ than other species-dominated communities, indicating that L. crispatus is one of the highest producers of lactic acid, a major antimicrobial agent found in lactobacilli [25]. D-lactic acid has been discovered in high concentrations in the vaginal secretions of women with $L$. crispatus dominant bacteria. This compound can inhibit the formation of EMMPRIN (extracellular matrix metalloproteinase inducer). EMMP RIN activates matrix metalloproteinase 8 [MMP-8], which has been linked to a higher risk of upper genital infections in women who have given birth prematurely. As a result, it's possible that D-lactic acid development is a key factor in preventing preterm birth. L. crispatus can also benefit the immune system. $L$. crispatus ATCC 33820 inhibits Candida albicans in vitro by modulating the expression of Toll-like receptors [TLR] 2/4, interleukin 8 [IL-8], and human-defensin 2 and 3 in epithelial cells [26]. These studies indicate that the prevalence of L. crispatus, a vaginal microbiota, is a strong indication of a stable vaginal microbial environment when taken together.

\section{Lactobacillus iners}

Lactobacillus iners was found in vagina, which is one of the most common vaginal species, and it was difficult to isolate. As opposed to L. Crispatus, which is primarily isolated from healthy women, is found in both healthy and BV-diagnosed women. The species was discovered by [27] and has eluded scientists for a long time [27] because it only grows on blood agar, not MRS or Rogosa. It suggests that women with $L$. iners have lower D-lactic acid concentrations, which may be one of the factors contributing to the high prevalence of BV in women. An in vitro study and genome analysis of $L$. iners, which had to prove the species' inability to produce D-lactic acid, backed up this argument [25]. L. iners has been also found in the microbiota form that exists between BV and normal microbiota. $L$. iners was found to be 
dominant even after BV was treated with metronidazole gel, according to Jakobsson and Forsum [28, 29].

\section{Bacterial vaginosis and infertility}

Gardnerella vaginalis grow in the reproductive tract which is a common cause of bacterial vaginosis and is controlled by Lactobacillus. This is most common in reproductive age women that may cause bacterial vaginosis, which causes millions of healthcare visits per year in the USA. It has been linked to infertility, pelvic inflammatory disorder, endometritis, and the possibility of contracting the human immunodeficiency virus.

As a result, the term BV is misleading because it refers to a condition that affects both the lower and upper genital tracts [30]. The composition and richness of microbial communities are often subject to "normal" fluctuations.

When the level of fluctuation becomes too great, these communities' microbial relationships must change from symbiotic to pathogenic disease. Abnormal bacterial colonization in the vaginal cavity and its condition of bacterial vaginosis which is related with pathological conditions such as infertility, which is associated with preterm birth (PTB), sexually transmitted diseases, and urinary tract infections are only a few examples [31-33]. Different disease symptoms (odor, epithelial integrity, discharge) have been related to particular bacterial species through research into metabolic markers of BV [34]. The use of $16 \mathrm{~S}$ rDNA sequencing technology revealed that in women with BV, the diversity and abundance of strictly anaerobic bacteria's populations have increased.

The same anaerobic species that grow in women's reproductive tract cause symptomatic BV (Gardnerella, Atopobium, Mobiluncus, and Prevotella), and it is also close to a bacterial population condition found in asymptomatic safe women [34, 35]. Women have a wide range of vaginal microbiomes, which may create bacterial signatures of bacterial vaginosis and temporal changes in the vaginal microbiome as a result of reproductive cyclicity, personal hygiene, and other factors.

Vaginal microbiomes are prone to temporal fluctuation, making it difficult to differentiate between BVcausing bacteria and opportunistic bacterial species that colonize and populate them in the reproductive tract as well as the vaginal cavity's climate shifts. Since the vaginal microbiome differs from person to person, determining the bacterial "signature" of BV as a result of temporal adjustments in the vaginal microbiome during reproductive cyclicity, personal hygiene, or other multiple variables is difficult. Developing effective BV therapies has become more complex due to the difficulty in detecting a causative pathogen. According to research on the different Lactobacillus species during pregnancy,
Lactobacillus iners expression was closely associated with PTB [36].

Similarly, which is shown that women have abnormal bacteria that colonize in the vaginal cavity, and bacterial vaginosis $[\mathrm{BV}]$ are the capability to increased risk for preterm birth [PTB], early pregnancy loss [37] and failure of IVF therapy [38]. These findings indicate that profiling the pregnancy-associated vaginal microbiome with more advanced "next-generation" sequencing could aid in identifying patients at high risk for PTB.

\section{Seminal microbiome and infertility}

Infertility affects $10-20 \%$ of couples around the world, and care can be stressful, intrusive, and expensive. The infertility male factor is responsible for almost half of all infertility cases $[39,40]$. There are so many genetic, immunological, and anatomical factors that may cause inflammation in the male genital tract which is related to male factor infertility [41]. Inflammation may trigger lower sperm quality through a variety of mechanisms, including impaired accessory gland secretion, oxidative stress, anatomical sperm tract obstruction, or microorganism's directly attacking the sperm [42]. These microorganisms may affect spermatozoon function without the use of reactive oxygen species or inflammatory cytokines by adhering directly to the spermatozoon or producing soluble factors capable of altering sperm motility and/or inducing apoptosis without causing inflammation $[43,44]$. The research of seminal microbiota is still in its early stages, and many concerns about how inflammation and urogenital infections that can affect male infertility which remains unanswered.

\section{Future directions}

The concept that the human reproductive tract's microbiome influences reproductive function as well as female reproductive efficiency, and offspring health and disease is gaining attraction; however, potential microbiome study must prioritize the field's major gaps and employ meticulously planned studies with broad sample sizes, sufficient control groups, and paired control specimens. To date, only the bacterial communities of the microbiomes of the reproductive tract have been studied. Protozoa, archaea, fungi, and viruses are all part of the microbiome. Other than bacteria, studies of microorganism species in the human microbiome are a promising research area because these microorganisms are likely to be present in the reproductive tract as well.

\section{Conclusions}

The importance of the microbial environment in various body locations, as well as the role of host-microbial interactions in physiological functions, has received a lot of attention in the last decade. Lactobacillus species 
colonize the female reproductive tract predominantly in healthy reproductive-age women, while disease, reproductive failure, and obstetric complications are related to the presence of dysbiotic or pathogenic bacteria. Metagenomics research has the ability to vastly improve our existing knowledge of vaginal microbial diversity in health and disease. Infertility testing can benefit from metagenomics profiling because it provides more precise diagnostic criteria. The reproductive tract's microbiome is being better understood.

\section{Abbreviations}

PCR: Polymerase chain reaction; LBR: Live birth rate; IVF: In vitro fertilization; NGS: Next-generation sequencing; BV: Bacterial vaginosis; PTB: Preterm birth: TLR: Toll-like receptors; MMP-8: Matrix metalloproteinase 8; EMMP RIN: Extracellular matrix metalloproteinase inducer

\section{Acknowledgements}

The authors acknowledge the Pacific Medical University and Hospital, for providing facilities and support during the study.

\section{Authors' contributions}

MV, ST, and LBY designed and wrote the manuscript. ST, LBY, and PT revised the article. All authors have read and approved the manuscript. MV, ST, and LBY contributed equally.

\section{Funding}

The study has been funded by the Department of Science and Technology Govt. of Rajasthan India.

Availability of data and materials

Not applicable.

\section{Declarations}

Ethics approval and consent to participate

Not applicable.

\section{Consent for publication}

Not applicable.

\section{Competing interests}

The authors declare that they have no competing interests.

\section{Author details}

'Department of Reproductive Medicine and Research, Pacific Medical University and Hospital Bhilon Ka Bedla, Udaipur, Rajasthan 313001, India. ${ }^{2}$ Department of Reproductive Medicine and Research, Pacific Medical University and Hospital Bhilon Ka Bedla, Udaipur, Rajasthan 313001, India.

Received: 28 May 2021 Accepted: 15 August 2021

Published online: 24 August 2021

\section{References}

1. Stumpf RM, Wilson BA, Rivera A, Yildirim S, Yeoman CJ, Polk JD, White BA, Leigh SR (2013 Dec) The primate vaginal microbiome: comparative context and implications for human health and disease. American journal of physical anthropology. 152:119-134. https://doi.org/10.1002/ajpa.22395

2. Cox MJ, Cookson WO, Moffatt MF (2013 Oct 15) Sequencing the human microbiome in health and disease. Human molecular genetics 22(R1):R88R94. https://doi.org/10.1093/hmg/ddt398

3. Jordan JA, Durso MB (2005 Nov 1) Real-time polymerase chain reaction for detecting bacterial DNA directly from blood of neonates being evaluated for sepsis. The Journal of Molecular Diagnostics. 7(5):575-581. https://doi. org/10.1016/S1525-1578(10)60590-9

4. Goldenberger D, Künzli A, Vogt P, Zbinden R, Altwegg M (1997 Nov 1) Molecular diagnosis of bacterial endocarditis by broad-range PCR amplification and direct sequencing. Journal of Clinical Microbiology. 35(11): 2733-2739. https://doi.org/10.1128/jcm.35.11.2733-2739.1997

5. Marchesi JR (2015) Ravel J. The vocabulary of microbiome research: a proposal. 31

6. Smith SB, Ravel J (2017 Jan 15) The vaginal microbiota, host defence and reproductive physiology. The Journal of physiology. 595(2):451-463. https:// doi.org/10.1113/JP271694

7. Kchouk M, Gibrat JF, Elloumi M (2017) Generations of sequencing technologies: from first to next generation. Biology and Medicine 9(3)

8. Madupu R, Szpakowski S, Nelson KE (2013 Jun) Microbiome in human health and disease. Science progress. 96(2):153-170. https://doi.org/10.3184/ $003685013 \times 13683759820813$

9. Cox MJ, Cookson WO, Moffatt MF (2013 Oct 15) Sequencing the human microbiome in health and disease. Human molecular genetics. 22(R1):R88R94. https://doi.org/10.1093/hmg/ddt398

10. Metzker ML (2010 Jan) Sequencing technologies-the next generation. Nature reviews genetics. 11(1):31-46. https://doi.org/10.1038/nrg2626

11. Xiao BB, Liao QP (2012 Apr 1) Analysis of diversity of vaginal microbiota in healthy Chinese women by using DNA-fingerprinting. Beijing da xue xue bao. Yi xue ban= Journal of Peking University. Health Sciences. 44(2):281287

12. Sirota I, Zarek SM, Segars JH Potential influence of the microbiome on infertility and assisted reproductive technology. InSeminars in reproductive medicine 2014 Jan (Vol. 32, No. 01, pp. 035-042). Thieme Medical Publishers.

13. Zhang D (2010) A study of vaginal flora. J. Pract. Obstetrics Gynecol. 26(2): 89-90

14. Song JH, Zheng JJ, Zhang HY, Tuo Y, Song SF (2011 Jan) Identification and analysis of vaginal lactobacilli in patients with bacterial vaginosis patients and healthy women in nationality of Pastoral area. Zhonghua fu chan ke za zhi. 46(1):41-44

15. Pelzer ES, Allan JA, Cunningham K, Mengersen K, Allan JM, Launchbury T, Beagley K, Knox CL (2011 Jul 1) Microbial colonization of follicular fluid: alterations in cytokine expression and adverse assisted reproduction technology outcomes. Human reproduction. 26(7):1799-1812. https://doi. org/10.1093/humrep/der108

16. Pelzer ES, Allan JA, Waterhouse MA, Ross T, Beagley KW, Knox CL (2013 Mar 12) Microorganisms within human follicular fluid: effects on IVF. PloS one. 8(3):e59062. https://doi.org/10.1371/journal.pone.0059062

17. Tachedjian G, Aldunate M, Bradshaw CS, Cone RA (2017 Nov 1) The role of lactic acid production by probiotic Lactobacillus species in vaginal health. Research in microbiology. 168(9-10):782-792. https://doi.org/10.1016/j. resmic.2017.04.001

18. Egbase PE, Al-Sharhan M, Al-Othman S, Al-Mutawa M, Udo EE, Grudzinskas JG (1996 Aug 1) Fertilization and early embryology: Incidence of microbial growth from the tip of the embryo transfer catheter after embryo transfer in relation to clinical pregnancy rate following in-vitro fertilization and embryo transfer. Human Reproduction. 11(8):1687-1689. https://doi.org/10.1 093/oxfordjournals.humrep.a019470

19. Fanchin R, Harmas A, Benaoudia F, Lundkvist U, Olivennes F, Frydman R (1998 Nov 1) Microbial flora of the cervix assessed at the time of embryo transfer adversely affects in vitro fertilization outcome. Fertility and sterility. 70(5):866-870. https://doi.org/10.1016/S0015-0282(98)00277-5

20. Moore DE, Soules MR, Klein NA, Fujimoto WY, Agnew KJ, Eschenbach DA (2000 Dec 1) Bacteria in the transfer catheter tip influence the live-birth rate after in vitro fertilization. Fertility and sterility. 74(6):1118-1124. https://doi. org/10.1016/S0015-0282(00)01624-1

21. Salim R, Ben-Shlomo I, Colodner R, Keness Y, Shalev E (2002 Feb 1) Bacterial colonization of the uterine cervix and success rate in assisted reproduction: results of a prospective survey. Human Reproduction. 17(2):337-340. https:// doi.org/10.1093/humrep/17.2.337

22. Selman H, Mariani M, Barnocchi N, Mencacci A, Bistoni F, Arena S, Pizzasegale S, Brusco GF, Angelini A (2007 Sep 1) Examination of bacterial contamination at the time of embryo transfer, and its impact on the IVF/ pregnancy outcome. Journal of assisted reproduction and genetics. 24(9): 395-399. https://doi.org/10.1007/s10815-007-9146-5

23. Moreno I, Codoñer FM, Vilella F, Valbuena D, Martinez-Blanch JF, JimenezAlmazán J, Alonso R, Alamá P, Remohí J, Pellicer A, Ramon D, Simon C (2016 Dec 1) Evidence that the endometrial microbiota has an effect on implantation success or failure. American journal of obstetrics and gynecology. 215(6):684-703. https://doi.org/10.1016/j.ajog.2016.09.075 
24. Witkin SS, Mendes-Soares H, Linhares IM, Jayaram A, Ledger WJ, Forney LJ (2013 Aug) Influence of vaginal bacteria and D-and L-lactic acid isomers on vaginal extracellular matrix metalloproteinase inducer: implications for protection against upper genital tract infections. MBio. 30:4(4)

25. Rizzo A, Losacco A, Carratelli CR (2013 Nov 1) Lactobacillus crispatus modulates epithelial cell defense against Candida albicans through Toll-like receptors 2 and 4, interleukin 8 and human $\beta$-defensins 2 and 3. Immunology letters. 156(1-2):102-109. https://doi.org/10.1016/j.imlet.2013. 08.013

26. Falsen E, Pascual C, Sjödén B, Ohlén M, Collins MD (1999 Jan 1) Phenotypic and phylogenetic characterization of a novel Lactobacillus species from human sources: description of Lactobacillus iners sp. nov. International Journal of Systematic and Evolutionary Microbiology. 49(1):217-221. https:// doi.org/10.1099/00207713-49-1-217

27. Ferris MJ, Norori J, Zozaya-Hinchliffe M, Martin DH (2007 Mar 1) Cultivationindependent analysis of changes in bacterial vaginosis flora following metronidazole treatment. Journal of clinical microbiology. 45(3):1016-1018. https://doi.org/10.1128/JCM.02085-06

28. Jakobsson T, Forsum U. Lactobacillus iners: a marker of changes in the vaginal flora?. Journal of clinical microbiology. 2007 Sep 1;45(9):3145-.

29. Spiegel CA, Amsel R, Eschenbach D, Schoenknecht F, Holmes KK (1980 Sep 11) Anaerobic bacteria in nonspecific vaginitis. New England Journal of Medicine. 303(11):601-607. https://doi.org/10.1056/NEJM198009113031102

30. Quan M (2010 Nov 1) Vaginitis: diagnosis and management. Postgraduate medicine 122(6):117

31. Brotman RM, Erbelding EJ, Jamshidi RM, Klebanoff MA, Zenilman JM, Ghanem KG (2007 Aug 1) Findings associated with recurrence of bacterial vaginosis among adolescents attending sexually transmitted diseases clinics. Journal of pediatric and adolescent gynecology. 20(4):225-231. https://doi. org/10.1016/j.jpag.2006.11.009

32. Dielubanza EJ, Schaeffer AJ (2011 Jan 1) Urinary tract infections in women Medical clinics. 95(1):27-41. https://doi.org/10.1016/j.mcna.2010.08.023

33. Ediriweera DS, Kasturiratne A, Pathmeswaran A, Gunawardena NK, Wijayawickrama BA, Jayamanne SF, Isbister GK, Dawson A, Giorgi E, Diggle PJ, Lalloo DG (2016 Jul 8) Mapping the risk of snakebite in Sri Lanka-a national survey with geospatial analysis. PLoS neglected tropical diseases. 10(7):e0004813. https://doi.org/10.1371/journal.pntd.0004813

34. Ravel J, Gajer P, Abdo Z, Schneider GM, Koenig SS, McCulle SL et al (2011 Mar) Vaginal microbiome of reproductive-age women. Proc Natl Acad Sci 15(108) (Supplement 1):4680-4687

35. Petricevic L, Domig KJ, Nierscher FJ, Sandhofer MJ, Fidesser M, Krondorfer et al (2014 May 30) Characterisation of the vaginal Lactobacillus microbiota associated with preterm delivery. Scientific reports. 4:5136

36. van Oostrum N, De Sutter P, Meys J, Verstraelen H (2013 Jul 1) Risks associated with bacterial vaginosis in infertility patients: a systematic review and meta-analysis. Human reproduction. 28(7):1809-1815. https://doi.org/1 0.1093/humrep/det096

37. Hyman RW, Herndon CN, Jiang H, Palm C, Fukushima M, Bernstein D, Vo KC, Zelenko Z, Davis RW, Giudice LC (2012 Feb 1) The dynamics of the vaginal microbiome during infertility therapy with in vitro fertilization-embryo transfer. Journal of assisted reproduction and genetics. 29(2):105-115. https://doi.org/10.1007/s10815-011-9694-6

38. Fredricks DN (2011 Aug 1) Molecular methods to describe the spectrum and dynamics of the vaginal microbiota. Anaerobe. 17(4):191-195. https:// doi.org/10.1016/j.anaerobe.2011.01.001

39. Agarwal A, Mulgund A, Hamada A, Chyatte MR (2015 Dec 1) A unique view on male infertility around the globe. Reproductive biology and endocrinology. 13(1):37. https://doi.org/10.1186/s12958-015-0032-1

40. Winters BR, Walsh TJ (2014 Feb 1) The epidemiology of male infertility. Urologic Clinics. 41(1):195-204. https://doi.org/10.1016/j.ucl.2013.08.006

41. Mändar R, Punab M, Korrovits P, Türk S, Ausmees K, Lapp E, Preem JK, Oopkaup K, Salumets A, Truu J (2017 Mar) Seminal microbiome in men with and without prostatitis. International Journal of Urology. 24(3):211-216. https://doi.org/10.1111/iju.13286

42. Condorelli RA, Russo Gl, Calogero AE, Morgia G, La Vignera S (2017 Nov 1) Chronic prostatitis and its detrimental impact on sperm parameters: a systematic review and meta-analysis. Journal of Endocrinological Investigation. 40(11):1209-1218. https://doi.org/10.1007/s40618-017-0684-0

43. Monteiro C, Marques PI, Cavadas B, Damião I, Almeida V, Barros N, Barros A, Carvalho F, Gomes S, Seixas S (2018 Jun) Characterization of microbiota in male infertility cases uncovers differences in seminal hyperviscosity and oligoasthenoteratozoospermia possibly correlated with increased prevalence of infectious bacteria. American journal of reproductive immunology. 79(6):e12838. https://doi.org/10.1111/aji.12838

44. Calogero AE, Duca Y, Condorelli RA, La Vignera S (2017 Nov) Male accessory gland inflammation, infertility, and sexual dysfunctions: a practical approach to diagnosis and therapy. Andrology. 5(6):1064-1072. https://doi.org/1 $0.1111 /$ andr.12427

\section{Publisher's Note}

Springer Nature remains neutral with regard to jurisdictional claims in published maps and institutional affiliations.

\section{Submit your manuscript to a SpringerOpen ${ }^{\circ}$ journal and benefit from:}

- Convenient online submission

- Rigorous peer review

- Open access: articles freely available online

High visibility within the field

- Retaining the copyright to your article

Submit your next manuscript at $\boldsymbol{\nabla}$ springeropen.com 